\title{
AN ANALYSIS OF GAMIFICATION IN EDUCATION. THE NEED FOR AN ETHICAL CODE
}

\author{
Silvia IORGULESCU, postdoctoral student in Political Sciences, \\ National University of Political Studies and Public Administration \\ Bucharest/Romania
}

\begin{abstract}
For a still young field, such as gamification, the multitude of research dedicated to the specific domain of gamification in education seems surprising. Some papers are focused on testing the formative and educational values of gamification; others concern its potentially negative impact or propose various ethical codes.

The present study aims to combine in a coherent approach these three disparate types of research, starting from the typologies of game elements implemented and the results obtained (positives = efficiency; negatives $=$ risk).

Given that (1) the results appear to be rather fragile, contradictory, inconclusive or in a tense relationship with the two typological extremes (e.g. the same mixing of game elements, PBL, is seen as "positive" and "negative" in different studies), (2) sometimes positive results are accompanied by cautious views or by pointing out potential obstacles or risks, (3) the highlighted risks concern broad categories of issues, the ethical perspective and the adequacy to educationalformative purposes becomes extremely necessary.

Assuming, however, that academic studies are as contradictory as selfreferential, this research seeks to expand the perspective with an additional and necessary counterpoint: a quantitative research aimed at collecting the opinions of potential beneficiaries of gamification in educational context on the necessity and content of an ethical code.
\end{abstract}




\section{Keywords}

Counterproductive effects; ethical code; ethical risks; game elements; gamification; gamification in education.

\section{METHODOLOGY}

The research used two different methods of analysis.

A. Systematic literature review

First, I considered it necessary to proceed to a systematic literature review, based on the fundamental research question:

Is gamification implemented in education so effective as to justify and compensate taking ethical risks for participants?

The basic question was segmented into several follow-up questions:

How is gamification applied in education and with what results?

What are the counterproductive effects of gamified educational design?

What risk reduction solutions are there?

\section{B. Quantitative research}

Secondly, on the basis of the conclusions drawn from the literature review, I have structured a questionnaire addressing the problems raised in the academic papers, in order to verify their degree of validity in relation to the perceived needs of potential beneficiaries of gamified learning activities.

The questionnaire concerned the perception of students on: the necessity for gamification in education, the objectives pursued, the potential risks, the need for an ethical code for gamification in the educational environment, the content of such a code. 


\section{INTRODUCTION}

Based on the well-known and often emphasized educational value of the games and the suggestive hypothesis launched by Prensky (2001) that new media and digital technologies have generated cognitive transformations in young generations, leading to new educational needs and preferences, gamification seems to be a very interesting and effective learning tool.

The beneficial effects of the mix between technology, playing and learning have been highlighted more than once: continuous learning, increasing learning efficiency (Cheng et al. 2013); supporting productive learning (Clark et al. 2016); improving attention behaviour (Navarro et al., 2003); increasing motivation and engagement (Woo 2014); encouraging problem-solving approaches, increasing the ability to retain information, the development of cognitive abilities that are not formally present in education, collaborative learning (Tang, 2009); the development of cognitive and affective capacities, the increase of gooddisposition during learning (Zhonggen 2019).

As we shall see, however, not always this enthusiasm for digital games or their expected potential has been confirmed by the practical application of gamification.

\section{SYSTEMATIC LITERATURE REVIEW}

A significant amount of meta-analysis on gamification in education is related to the game elements that can be used (number, selection, combinations) and the measured/reported educational outcomes. Others studies take it one step further, trying to find correlations between a specific element and the responses obtained/measured. The papers are also interested in the typology of obtained results (positive, negative and inconclusive reports).

Some studies, fewer, but more strongly individualized, focus on the negative effects of gamification in education. As part of the proposed solutions to make gamification in education more efficient and to reduce potential risks, I was also looking at another category of papers, which address the design of gamification 
in the educational environment through an ethical perspective and propose examples of specific codes.

Question 1: How is gamification applied in education and with what results?

To answer this question, I will propose, in the limits of this paper, a working definition. Thus, by applying the classic definition of gamification (Deterding 2011) to education, one can say that it involves the implementation of game elements in a non-game context, in order to achieve results with formative and educational valences. Two categories of processes are therefore highlighted as important: the selection and application of the game elements and the validation of the expected results/measurements of the outcomes obtained, from the perspective of their educational value.

In analysing these processes and in order to outline the effectiveness of gamification design in education, I will rely an the conclusions extracted from a number of studies which address the implementation of game elements and the results obtained: 128 empirical papers (Majuri et al., 2018); 51 empirical and 11 theoretical studies (Dichev and Dicheva 2017); 40 empirical studies (Alomari et al. 2019); 32 papers (Ofosu-Ampong, 2020); 22 secondary studies (Hyrynsalmi et al. 2017); 17 empirical studies (Toda et al. 2018).

Regarding the selection and application of the game elements, there are several relevant conclusions:

- The systematic use of several elements, in average between 3 and 4 (Dichev and Dicheva, 2017; Majuri et al. 2018), in various mixes (Dichev and Dicheva 2017; Alomari et al. 2019), without a clear justification for the choice (Dichev and Dicheva 2017)

- The preference for the PBL system (Dichev and Dicheva 2017; Majuri et al. 2018; Alomari et al. 2019; Ofosu-Ampong 2020; Toda et al. 2018), which is known to have the lowest level of abstraction, perceived by several researchers as being responsible for triggering an extrinsic, "artificial" motivation and with short-term effects 


\title{
AN ANALYSIS OF GAMIFICATION IN EDUCATION. THE NEED FOR AN ETHICAL CODE
}

\author{
Silvia IORGULESCU, postdoctoral student in Political Sciences, \\ National University of Political Studies and Public Administration \\ Bucharest/Romania
}

\begin{abstract}
For a still young field, such as gamification, the multitude of research dedicated to the specific domain of gamification in education seems surprising. Some papers are focused on testing the formative and educational values of gamification; others concern its potentially negative impact or propose various ethical codes.

The present study aims to combine in a coherent approach these three disparate types of research, starting from the typologies of game elements implemented and the results obtained (positives = efficiency; negatives $=$ risk).

Given that (1) the results appear to be rather fragile, contradictory, inconclusive or in a tense relationship with the two typological extremes (e.g. the same mixing of game elements, PBL, is seen as "positive" and "negative" in different studies), (2) sometimes positive results are accompanied by cautious views or by pointing out potential obstacles or risks, (3) the highlighted risks concern broad categories of issues, the ethical perspective and the adequacy to educationalformative purposes becomes extremely necessary.

Assuming, however, that academic studies are as contradictory as selfreferential, this research seeks to expand the perspective with an additional and necessary counterpoint: a quantitative research aimed at collecting the opinions of potential beneficiaries of gamification in educational context on the necessity and content of an ethical code.
\end{abstract}




\section{Keywords}

Counterproductive effects; ethical code; ethical risks; game elements; gamification; gamification in education.

\section{METHODOLOGY}

The research used two different methods of analysis.

A. Systematic literature review

First, I considered it necessary to proceed to a systematic literature review, based on the fundamental research question:

Is gamification implemented in education so effective as to justify and compensate taking ethical risks for participants?

The basic question was segmented into several follow-up questions:

How is gamification applied in education and with what results?

What are the counterproductive effects of gamified educational design?

What risk reduction solutions are there?

\section{B. Quantitative research}

Secondly, on the basis of the conclusions drawn from the literature review, I have structured a questionnaire addressing the problems raised in the academic papers, in order to verify their degree of validity in relation to the perceived needs of potential beneficiaries of gamified learning activities.

The questionnaire concerned the perception of students on: the necessity for gamification in education, the objectives pursued, the potential risks, the need for an ethical code for gamification in the educational environment, the content of such a code. 


\section{INTRODUCTION}

Based on the well-known and often emphasized educational value of the games and the suggestive hypothesis launched by Prensky (2001) that new media and digital technologies have generated cognitive transformations in young generations, leading to new educational needs and preferences, gamification seems to be a very interesting and effective learning tool.

The beneficial effects of the mix between technology, playing and learning have been highlighted more than once: continuous learning, increasing learning efficiency (Cheng et al. 2013); supporting productive learning (Clark et al. 2016); improving attention behaviour (Navarro et al., 2003); increasing motivation and engagement (Woo 2014); encouraging problem-solving approaches, increasing the ability to retain information, the development of cognitive abilities that are not formally present in education, collaborative learning (Tang, 2009); the development of cognitive and affective capacities, the increase of gooddisposition during learning (Zhonggen 2019).

As we shall see, however, not always this enthusiasm for digital games or their expected potential has been confirmed by the practical application of gamification.

\section{SYSTEMATIC LITERATURE REVIEW}

A significant amount of meta-analysis on gamification in education is related to the game elements that can be used (number, selection, combinations) and the measured/reported educational outcomes. Others studies take it one step further, trying to find correlations between a specific element and the responses obtained/measured. The papers are also interested in the typology of obtained results (positive, negative and inconclusive reports).

Some studies, fewer, but more strongly individualized, focus on the negative effects of gamification in education. As part of the proposed solutions to make gamification in education more efficient and to reduce potential risks, I was also looking at another category of papers, which address the design of gamification 
in the educational environment through an ethical perspective and propose examples of specific codes.

Question 1: How is gamification applied in education and with what results?

To answer this question, I will propose, in the limits of this paper, a working definition. Thus, by applying the classic definition of gamification (Deterding 2011) to education, one can say that it involves the implementation of game elements in a non-game context, in order to achieve results with formative and educational valences. Two categories of processes are therefore highlighted as important: the selection and application of the game elements and the validation of the expected results/measurements of the outcomes obtained, from the perspective of their educational value.

In analysing these processes and in order to outline the effectiveness of gamification design in education, I will rely an the conclusions extracted from a number of studies which address the implementation of game elements and the results obtained: 128 empirical papers (Majuri et al., 2018); 51 empirical and 11 theoretical studies (Dichev and Dicheva 2017); 40 empirical studies (Alomari et al. 2019); 32 papers (Ofosu-Ampong, 2020); 22 secondary studies (Hyrynsalmi et al. 2017); 17 empirical studies (Toda et al. 2018).

Regarding the selection and application of the game elements, there are several relevant conclusions:

- The systematic use of several elements, in average between 3 and 4 (Dichev and Dicheva, 2017; Majuri et al. 2018), in various mixes (Dichev and Dicheva 2017; Alomari et al. 2019), without a clear justification for the choice (Dichev and Dicheva 2017)

- The preference for the PBL system (Dichev and Dicheva 2017; Majuri et al. 2018; Alomari et al. 2019; Ofosu-Ampong 2020; Toda et al. 2018), which is known to have the lowest level of abstraction, perceived by several researchers as being responsible for triggering an extrinsic, "artificial" motivation and with short-term effects 
- The very rare application of a single game element (in 11 studies at Dichev and Dicheva 2017; 7 studies at Majuri et al. 2018), which makes it difficult to estimate the exact effects of an element on educational goals

- The difficulty to correlate a game element, a set of game elements or their interaction with a particular type of response: motivational, behavioural, etc. (Dichev and Dicheva 2017; Majuri et al. 2018, OfosuAmpong 2020).

Regarding the reported results:

- The most often mentioned outcomes are: involvement; performance; knowledge retention; motivation; attention; satisfaction; competence (Dichev and Dicheva 2017); perception of amusement, fun; engagement; flow; perceived utility and effectiveness; relatedness; competition; recognition; motivation; perceived competence; interest; satisfaction (Majuri et al., 2018); increased motivation, involvement and participation, improving skills and performance (Alomari et al. 2019); cognitive belief and behaviour; attitude; performance; improved learning; interpersonal relationship; motivation; engagement (OfosuAmpong 2020)

- these outcomes can be grouped in ad-hoc typologies, as exemplified in some studies: affective, behavioural, cognitive, another/other (Dichev and Dicheva 2017); "psychological", i.e. affective, cognitive, social, psychological, attitudinal and, respectively, "behavioral" (Majuri et al. 2018)

- In terms of efficiency, the results are mixed and evaluated as:

○ positive: Majuri et al. (2018) shows that $71.43 \%$ of the empirical studies analysed had a beneficial impact, but the counterweight of those who provided null or negative responses urge the authors to caution; Hyrynsalmi et al. (2017), although from a critical perspective, mention that the vast majority of secondary studies have a positive view of gamification

- however, it should be noted that even studies that identify positive results also draw attention to obstacles or precautions: (1) unfamiliarity of students with gamification; 
fear of failure (which may lead to a lack of student participation); frustration and loss of self-confidence (because of changes in competency levels); different levels of motivation (gamification may not motivate all students the same, due to personal differences between participants) (Alomari et al. 2019); (2) the existence of several factors, let us say external, that may affect the experience itself and possibly the educational results obtained, such as: demographics, personality factors, learning styles, spatial and temporal context (Majuri et al. 2018)

- inconclusive: Dichev and Dicheva (2017) believe that the results are rather inconclusive (the vast majority of the empirical works analysed - 25/41 - report inconclusive outcomes)

○ negative: Hyrynsalmi et al. (2017), Toda et al. (2018); a more extended analysis of negative results will be presented below

- the PBL system offers a contradictory image:

- for Alomari (2019), the points would encourage motivation and engagement, a positive and fun competition, an enjoyable experience, performance and teamwork; badges would stimulate motivation, sense of competence, involvement, active learning, social interaction, performance; leaderboards would be useful for stimulating competition, performance, motivation, involvement, the sense of reputation

- for Toda et al. (2018), the leaderboard has the strongest influence on several negative effects, followed by points and badges, both with the same level of impact; the PBL combination was found in 10 analysed studies, which led the authors to conclude that the negative impact may be associated with their use (the PBL approach may not be suitable for certain contexts, especially if not well designed or structured upon instructional and motivational design theories) 
Question 2: What types of negative impact have been reported?

Up to this point, it still seems rather difficult to clearly establish the degree of effectiveness for the gamified educational designs implemented, in terms of a coherent and logic connection between the selection and application of the game elements (number, mix, interaction) and the reported results. Moreover, the measured outcomes seem variable and unstable, impossible to undoubtedly and repeatedly connect to specific educational results.

In the absence of results that have conclusive, relevant educational valences, it is necessary to turn our attention to the reported negative impact of gamified educational activities, in order to identify and highlight the "rentability" of the process.

In this section, I will summarize the findings of two sets of research: secondary critical studies (17 empirical studies, Hyrynsalmi et al. 2017; 22 paper reviews Toda et al. 2018) and primary critical studies (Buck 2017; Boulet 2016; Kim and Werbach 2016).

The goals, approach and argumentation of the selected studies are variable, and the motivation for their inclusion has been to offer a wider perspective of the gamified educational systems and to point out the diversity of issues raised to date in relation to gamification and, in particular, to its application in education. Of these studies,

- three propose a conceptual framework for the negative effects:

○ Toda et al. (2018) identifies 4 major negative effects: indifference, loss of performance, undesired behaviour and declining effects; o Hyrynsalmi et al. (2017) divides the negative effects into two thematic categories: limitations of gamification (lack of producing optimal results) and the harmful implications of gamification; $\circ$ Kim and Werbach (2016) propose a general risk analysis framework that can work in several areas, including education, and show that potential ethical issues can arise either from the user's interaction with the game and, respectively, with the real world (physical/psychological harms and the influence of 
perception of moral norms) or from some distortions in the relation between designer and users (exploitation and manipulation of participants).

- three other studies highlight potential negative valences, such as the fragilization of learning process or the violation of pedagogical and ethical norms:

○ Boulet (2016) addresses the relationship between rewards (materialized by points, badges, etc.) and the process of stimulating, maintaining and enhancing motivation for educational purposes. It's worth mentioning that the problem of adverse effects of rewards is often reiterated and analysed in general studies (e.g., Bénabou and Tirole 2003; Marczewski 2013) o Buck (2017) starts by comparing gamification with education, as two contrasting, if not incompatible logical systems and presents perhaps the most comprehensive series of negative effects $\circ$ Jones (2015) emphasizes the main problems in implementing gamified learning modules and proposes targeted solutions that would, ideally, eliminate these problems; the paper, to which we will return, is, in fact, aimed at the regulation of the field of gamification in an educational context from an ethical point of view and connects the risks reported to several solutions.

For the strict purpose of this work, I will separate the negative impact typologies that emerge from the research mentioned in three thematic categories, noting that this categorization is rather a "technical" one; in reality, the effects are intertwined and they can be equally integrated into several categories:

A. Ethical risks: tendentious control over the process of knowledge acquisition and social interaction (Buck, 2017); manipulation of users through lack of transparency of goals (Kim and Werbach, 2016); limited decision-making and behavioural autonomy by associating rewards with a certain type of behaviour, desired or expected by the designer of gamification (Kim and Werbach, 2016); public humiliation and unfavourable comparisons by using 
hierarchies (leaderboards), public display of the results (Kim and Werbach, 2016; Jones, 2015); uncertainty about the use of personal data (Jones, 2015).

B. Counterproductive effects in the teaching-learning-assessment process (understood as a complex process, which involves acquiring not only knowledge, but also skills and competences)

a. Cognitive:

success in the game, but not necessarily in the task at hand; distraction from the main purpose of the gamified system (Hyrynsalmi et al. 2017); focus on game mechanics rather than on the task at hand (Toda et al. 2018); loss or decrease in performance (Kim and Werbach, 2016; Toda et al. 2018); lack of improvement in learning, no cognitive or performance impact (Toda et al., 2018); valuing instant feedback, which can lead to a process of learnification (Buck 2017); transforming learning content into pretexts for obtaining virtual rewards, thus collecting knowledge that no longer fulfils its formative role (Buck 2017); facilitation of activity instead of cognitive effort (Buck 2017); personal or educational needs that cannot be met by gamification (Jones 2015).

b. Psychological-behavioural-affective:

b1. Motivation: demotivation (Hyrynsalmi et al. 2017); no effect on motivation and involvement, gradual loss of motivation and engagement (Toda et al., 2018); decreased desire to persist in learning, momentary performance, loss of the intrinsic motivation to learn (Boulet 2016); refuse to participate being assigned the wrong role (against one's personality) (Jones 2015).

b2. Impact of rewards: performing only when rewarded (Hyrynsalmi et al. 2017); frustration over not getting badges (Toda et al., 2018); reward becomes the end itself and transfers the focus from the task at hand (Boulet 2016); refuse to participate - concerns of how the pointsified progress is evaluated (Jones 2015).

b3. Collaboration/competition: limiting the capacity of collective action and teamwork (Hyrynsalmi et al. 2017); excessive competition (Toda et al. 2018); excessive spirit of competition, unfavourable to collective cooperation and mental well-being of users (Kim and Werbach 2016). 
b4. Game experience: experience has been qualified as unappealing/waste of time; indifference to the gamified system (perceived as affective neutral), lack of interest (preference for traditional learning methods) (Toda et al. 2018); decrease in the desire to participate in gamified activities (Kim and Werbach 2016); danger of isolation of the student (Buck 2017); possible lack of attractiveness to the game for some users; failure to effectively mix fun with meaningful educational activities (Jones 2015).

C. Systemic risks (included here are those risks that attack the core of the education system and its scope):

alienation from educational practices; virtualization of the school; loss of meaning for the teacher's role; de-pedagogization of educational practices; neglect of the diligent and coordinated effort of education (Buck 2017); neutrality, indifference in relation to the fundamental values of life, if, supposedly, gamified activities support (directly or in subtext) war, social hatred, lack of value of life (Kim and Werbach 2016).

Q3: What risk reduction solutions exist?

Of course, the negative effects cannot be regarded as "absolute", as, in the course of this research, I have tried to show that the enthusiasm for the educational results of gamification should also be tempered. However, the sets of potential issues raised must have an ethical echo in the future implementation of educational gamified systems, in terms of finding a balance between the objectives of implemented systems and the need for precaution regarding the risks.

Consequently, this section will focus on a set of three works: (Jones 2015; Rootman-le Grange et al. 2016; Versteeg 2013), which summarizes several directions of action, including the management of ethical, pedagogical and technological problems, such as the adequacy of gamified activities to educational purposes, the congruence of game objectives with formativeeducational ones, etc. 
o Jones (2015) proposes solutions to address identified problems, without systematizing them into categories

o Rootman-le Grange et al. (2016) start from the idea that gamification users can suffer a technological shock with moral and social repercussions, given the broad development of gamification, without the field itself being "regulated". Thus, the authors propose a set of rules, divided into 4 categories: honesty and transparency; integrity; quality; respect.

o Versteeg (2013) proposes a moral framework of gamification in education, divided into 4 sections: principles and moral values; conceptual investigation (on how gamification can affect users and their values); stakeholder involvement; evaluation and reiteration of processes.

Because each author proposes a specific terminology and a personal conceptual framework of the solutions for an ethical code on gamification in educational context, for the purpose of this study and for a greater clarity of solutions, I will use an ad hoc framework. It aligns, roughly, with the framework used for the systematization of risks.

\section{A. Ethical standard}

a. Transparency: clearly explaining the educational purpose of gamification; explaining how progress reports in the game are translated into grades (Jones, 2015); transparency in relation to implementation; explaining the connection between grades and points; clear communication about what is expected of the participants (Rootman-le Grange et al., 2016); transparency on expected results (Versteeg 2013)

b. Privacy and safety: privacy of personal and participation data; avoiding the public exposure of results (Jones 2015); the use of numbers, instead of names, for leaderboards (Rootman-le Grange et al. 2016); protection of privacy, anonymity; cyber security (Versteeg 2013)

c. Integrity: simulating a positive competition (competition of the students should be with themselves, not with the others) (Rootman-le Grange et al. 2016); eliminating suspicions of behavioural manipulation (Jones 2015); eliminating behavioural manipulation; lack of risks in the use of persuasive technology; evaluation and process reiteration, which would serve to correct the process as 
ethical design issues are identified and addressed; conceiving scenarios to envision and systematize potential positive and negative results (Versteeg, 2013) d. Respect: respect for participants as students, not as avatars (Rootman-le Grange et al. 2016); non-discrimination (Versteeg 2013).

\section{B. Educational and formative solutions}

a. Knowledge: teachers must learn the technical principles of designing activities (beyond points, badges and leaderboards) and be able to understand the participants' learning needs and player typologies (Jones 2015)

b. Quality: overlapping learning content with stories (creating story series for activities and using this narrative thread to make students understand learning goals); assessment and recognition of users' progress by multiple methods (other than PBL) (Jones 2015); designing and implementing well-thought-out and qualitative activities (Rootman-le Grange et al. 2016)

c. Adequacy: linking gamified activities with clear learning objectives (design should aim to achieve these goals, develop creativity and critical thinking, enable skills, be attractive) (Jones 2015); avoiding the use of gamification only because it is fashionable and use it only if it is really efficient in the proposed educational activities (Rootman-le Grange et al. 2016); offering guiding so that students are not "caught" too much in the game, thus forgetting the learning objective (Rootman-le Grange et al. 2016).

All these proposals can be used as a conceptual base in designing a necessary ethical code for gamification in the educational context. It goes without saying that some risks are more manageable than others. Surely, some risks will always circumvent the strictness of a code. However, such a code should be intended to prevent risks, as well as to permit the participants to access an effective remedy, if the norms are broken. Therefore, a more in-depth study of the negative effects could serve as a theoretical and practical base for designing a code as comprehensive as possible, for the triple protection of students, instructors and system. 


\section{QUANTITATIVE RESEARCH}

This section seeks to complement academic opinions with the views of potential participants in gamified educational activities and to identify the extent to which the former are validated and/or nuanced by the perceptions of the beneficiaries. Thus, it will focus on the results of a quantitative research: the application of questionnaires on a representative target group (college students) for potential beneficiaries of the implementation of gamification in education.

The research was carried out between 14 March and 10 May 2021. The target group was represented by students from Romania. The application of the 276 online questionnaires was carried out in a formal, structured framework, as part of the work tasks of the participants' internship.

Target group profile:

- Romanian college students, nationwide level (the locality of origin was requested in the questionnaire)

- with a heterogeneous educational background: registered with state and private educational institutions; very diverse universities, faculties and specializations (Letters, Law, Chemistry, Marketing, Foreign Languages, Medicine, Military Academies, Journalism, Physical Education and Sport, etc.)

- in terms of age:

o 20 years old (106 respondents $-38.4 \%$ )

o 19 years old (56 respondents $-20.3 \%$ )

o 21 years old ( 35 respondents $-12.7 \%$ )

o 22 years old (17 respondents $-6.2 \%$ )

Since the answers are themselves very conclusive, I will only make some succinct observations.

First of all, it should be noted that the students responded to the questionnaire on the basis of their own knowledge of gamification, without prior training on the subject or on the content of the questions.

Then, from a formal point of view, some questions were Yes/No type, others were Multiple Choice Questions. 
Yes/No questions were mandatory, the others were optional. However, the vast majority of participants also answered the optional questions.

With regard to content, it can be observed that respondents, for the most part, perceive gamification as necessary in an educational context (Fig. 1).

\section{Question 1: Do you think the gamification is useful for educational purposes? (mandatory, 276 responses)}

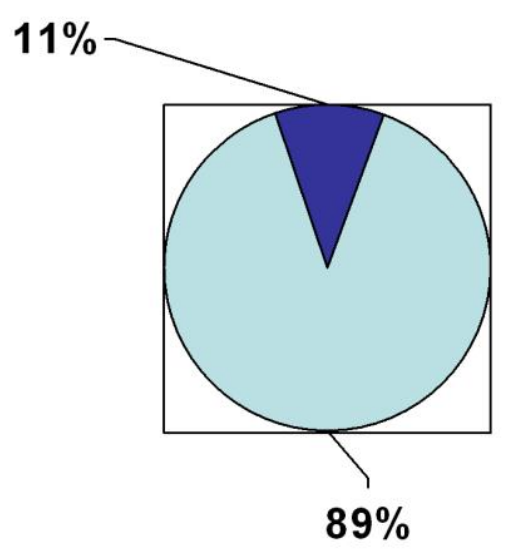

Figure 1. The perceived utility of gamification in educational context

The goals that, in respondent's opinion, seem most appropriate to the educational context validate, to some extent, the current opinions relative to the gamification objectives identified in research (motivation, engagement, socioaffective and cognitive objectives).

The options for involvement, even if they seem to overlap semantically, are nevertheless hierarchized according to the degree of involvement. For example, "raising/increasing interest in a subject/discipline" would be a first step in motivation, "increasing willingness to participate in activities" would be a second stage, and "increasing involvement in activities" would amount to a higher degree of motivation. 
The rankings show something interesting in the relationship with the degrees of implication: the highest degree of engagement is seen as the most important. The cognitive goals rank second in respondents reporting, while the social roles (competition and collaboration) rank third (Fig. 2).

\section{Question 2: What do you think would be the objectives of the gamified education systems? (optional, 276 responses)}

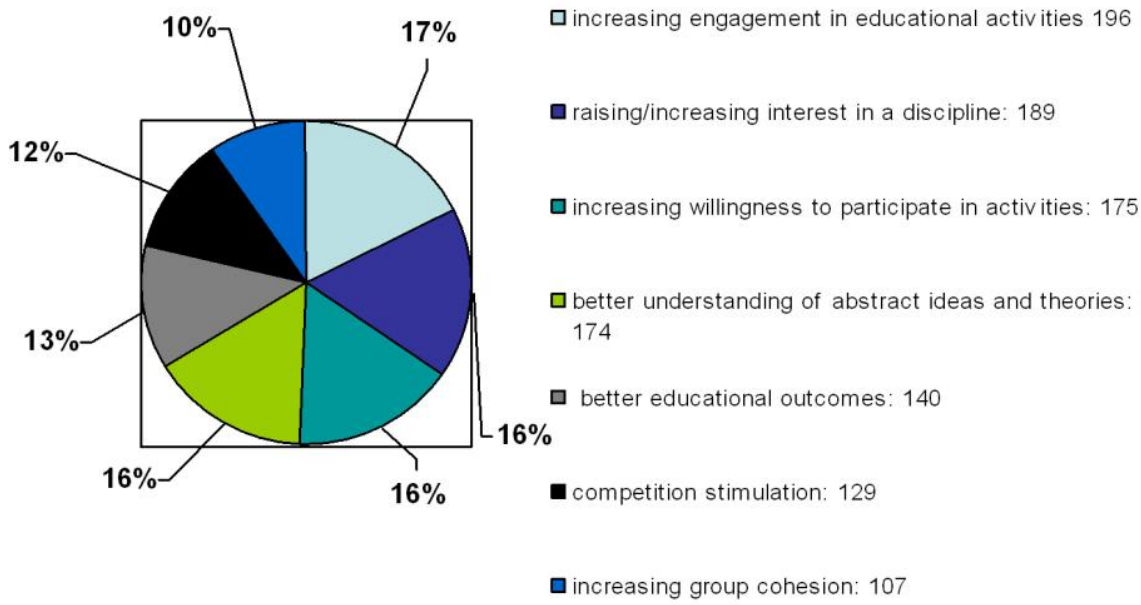

Figure 2. The perceived outcomes of gamification in educational context

Participants also perceive, in the majority, the existence of potential risks of gamified educational activities (Fig. 3).

From the point of view of the respondents, these negative effects would impact on cognitive objectives (learnification, concentration on the game and not on the task at hand) and socio-affective outcomes (possibly exclusion of those who are not passionate with the game, negative competitiveness) and could induce systemic risks (school virtualization) (Fig. 4). 
Question 3: Do you consider that gamified educational activities may also have counter-productive/negative effects? (mandatory, 276 responses)
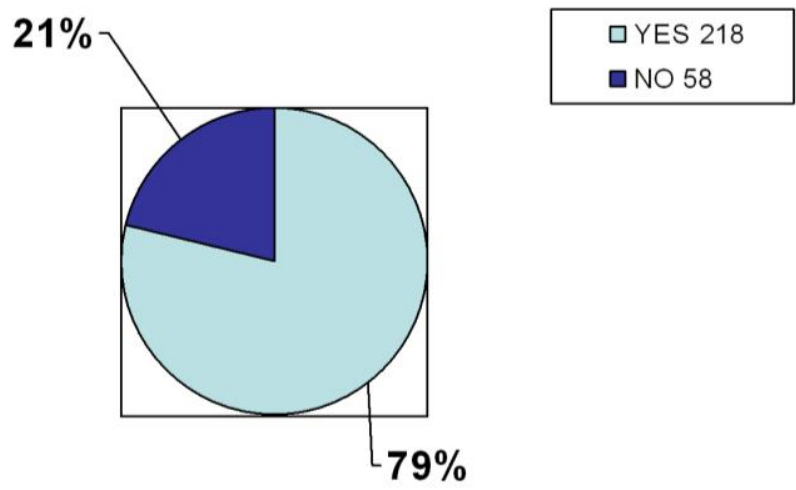

Figure 3. The perception on negative impact of gamified educational activities

Question 4: What do you think potential negative effects could be? (optional, 267 responses)

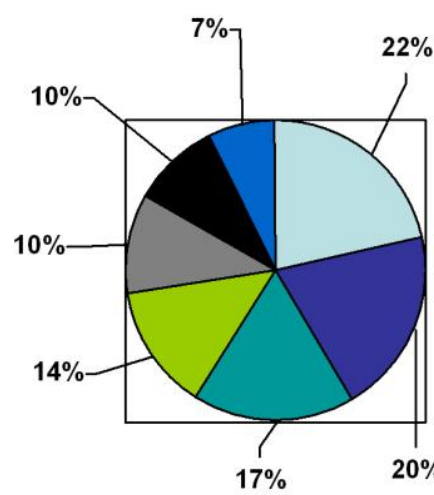

$\square$ associating learning with points, badges, etc. rather than acquiring knowledge: 151

$\square$ focusing more on game and less on learning: 137

$\square$ exclusion of some students from learning activities (if not attracted by video games): 120

$\square$ excessive competitiveness between the participants: 96

$\square$ school virtualization: 72

neglect of participants' learning typologies: 68

$\square$ depedagogization of educational practices: 50

Figure 4. The perception on negative potential effects of gamified educational activities 
The positive perception on the need to design an ethical code for gamification in education is also conclusive (Fig. 5).

\footnotetext{
Question 5: Do you think it would be important to design a code of ethics for gamification in educational context? (mandatory, 276 responses)
}

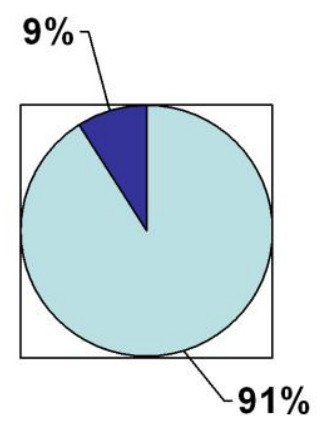

$\square$ YES 251
$\square$ NO 25

Figure 5. The perception on the utility of an ethical code for gamification in educational context

The content of such a code would need to address protecting personal data, respecting the rights of players, preventing the use of gamification for noneducational purposes, linking gamified activities with clear learning objectives. As noted, the protection measures should be directed towards both ethical and ethical-pedagogical measures (Fig. 6).

It can therefore be said that the study showed a clear awareness of the risks and their hierarchy, the perceived need for an ethical code and also a prioritization of provisions included in the mentioned code. 
Question 6: What purposes could such an ethical code have? (optional, 276 responses)

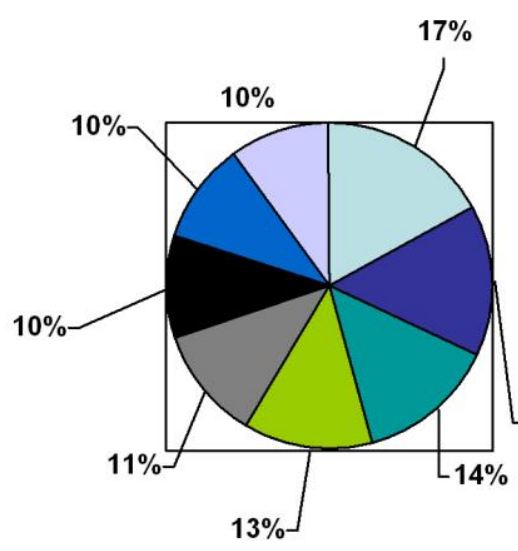

$\square$ protecting users' personal data: 196

$\square$ respecting the rights and freedoms of participants: 167

$\square$ preventing the use of gamification for noneducational purposes: 154

$\square$ correlating gamified activities with clear educational purposes: 144

$\square$ transparency about objectives and the expected results: 130

$15 \%$

avoid public exposure of participants' results:

116

$\square$ quality gamified activities design: 115

$\square$ transparency about correlating the points, badges, etc. with grades: 112

Figure 6. The perception on the utility of an ethical code for gamification in educational context

\section{CONCLUSIONS AND RECOMMENDATIONS}

In this study, I analysed, based on the data available in the literature, the utility and the "rentability" of the application of gamification in an educational context. I started, logically, from the game elements used (number, typologies, mixes, interactions), in order to identify the results of their implementation. The conclusions were not necessarily encouraging. From the overview of empirical studies and meta-analysis, one cannot clearly deduce the necessity, relevance and impact of the development of educational approaches and scenarios through gamification. Of course, it is appropriate to mention that more studies are needed for more consistent results. 
Thus, the next logical step was to identify reports of negative results, which constitute potential risks to the very educational and formative valences that gamification wants to support. I have shown that, at least as a possibility, a number of ethical and potential risks can influence the educational endeavors or/and distort the pedagogical norms. They cover a large number of typologies, which makes them susceptible to, at minimum, be analysed more carefully and, maximally, be addressed by targeted responses, in the form of an ethical code. In order to extend the academic perspective and, to the rigor, to validate these opinions synthesized from the meta-analysis, I considered it necessary to obtain the opinion of the potential beneficiaries of gamification - and of the subjects of the educational process - on the perceived risks and the need to manage them through an ethical code.

The results have shown that the students perceive, on the one hand, the need for gamification as an educational tool and, on the other hand, are aware of the risks posed by the gamified educational systems and of the necessity to be protected against potential negative effects.

I have made it clear earlier, that other empirical studies are certainly needed to accurately outline the potential of gamification in education. But, on the other hand, gamification is not in itself good or bad and the nuances it acquires depend on its application.

That is why I believe that it is necessary, even - or especially - at this stage of testing methods, results and efficiency, for gamification to be applied in accordance with ethical and educational norms. Consequently, while gamification still needs testing to reveal its potential, through successive reiterations and refinements, the system and the beneficiaries of education must be protected from the highlighted side effects. It should not be forgotten that education is an ecosystem, with specificities and strict roles, in which gamification must find its own place: gamification should adapt to education, serving its purposes, and not the other way around. Under no circumstances shall it warrant the permanence of vain, possibly non-productive or harmful tests affecting the system and the beneficiaries. 


\section{LIMITATIONS}

Regarding empirical studies, there is a high heterogeneity at multiple levels: (1) variability of the proposed focus targets: focus on the user (behavioural or cognitive impact; categories of users; user perception; measurements of results) or on the gamification process (gamification elements and gamified platforms); (2) variability of the levels of education at which gamified activities have been implemented and, therefore, of the ages of the users; (3) lack of homogeneity in the selection of implemented elements (diversity of tested elements, diversity of combinations, variation in the number of implemented elements); (4) the multiplicity and variety of disciplines in which gamified activities have been involved, the variability of learning content; (5) the heterogeneity of gamified activities.

Moreover, it is worth mentioning the great number of review papers carried out on the basis of the empirical studies, in an attempt to achieve a cartography of the field, with various purposes (proving the functionality of gamification, systematizing the elements used, analysing the goals and results, analysing the ethical perspective, etc.).

Of course, the combining of these many multiform-applied variables results in a huge diversity of specific situations, which prevents us, for the time being, to reduce the extant experiences in gamified education to a norm.

Regarding the quantitative research, not all possible negative effects, nor all proposals for ethical code content could have been subjected to student validation, due to their lack of knowledge of the specialized aspects of gamification.

Therefore, and in order to collect unified opinions, representative typologies of ethical and educational risks were chosen.

The research was conducted at national level, on a targeted group that may prove relevant in highlighting the need for the beneficiaries of education to participate in defining the utility, the roles and the risks of gamification. More advanced, long-term studies are required, with an extended group. 


\section{FUTURE STUDIES}

During my research on the application of ethical norms in the design of educational gamification, I was also interested in yet another important aspect of the problem. The fact that the beneficiaries of the education system are mainly children and young adults, categories par excellence vulnerable, should raise the question of the degree of protection granted to them, which must be very high. Moreover, it should not be ignored that, in the interaction between gamification (game and technology) and education, the fundamental right that must be enhanced is the right of education. Therefore, I believe that future research could address the issue of gamification beyond an ethical code, in the light of its potential to enhance/endanger rights.

Thus, as a collateral work to this study, I sought the opinion on the subject of several National Human Rights Institutions (NHRI), which, over time, have taken interest in the way of respecting and promoting rights in interaction with digital environment. Thus, five NHRI (Danish Institute for Human Rights, German Institute for Human Rights, Netherlands Institute for Human Rights, The Equality Ombudsman of Sweden, Romanian Institute for Human Rights) responded to my questionnaire: "Analysis of the gamification design in the educational environment - a human rights-based perspective".

While not offering an in-depth analysis of these answers in the current paper, I will briefly mention only two significant aspects.

First, in the light of the received answers, one may assert that the gamification applied in an educational context may have the potential to generate violations of rights (4 answers - Yes; 1 answer - Maybe).

Secondly, in terms of the ranking of rights that could, potentially, be violated by inadequately applying gamification in educational activities, the most selected answers were:

- collection, storage, processing, use of personal data (protection of privacy and personal data) (4 answers);

- discrimination between types of participants (not all participants are equally attracted to video games) (right to protection against discrimination) (4 answers); 
- public display of results through leaderboards, which can lead to a negative school climate, bullying, etc. (nondiscrimination, data protection, protection against violence) (2 answers);

- gamification of learning activities about sensitive issues (inequality, discrimination, racism, etc.), which can, in extremis, conduct to the trivialization of these topics, misunderstanding of subjects, lack of respect etc. (right to protection against discrimination) ( 2 answers);

- differentiated access to technology and devices of the participants (right to protection against discrimination, Internet access, right to education) (1 answer);

- generating potentially aggressive competitions between participants and encouraging competition, instead of cooperation (right to peaceful assembly and association) (1 answer);

- risk of behavioural manipulation, knowing that gamification is based on psychological processes that can encourage behavioural change (protection against violence) (1 answer).

I will conclude by saying that, certainly, the future collection of more opinions is necessary in this area and that this first attempt can be seen as a starting point.

\section{ACKNOWLEDGEMENTS}

I must thank the students who were willing to participate in this research, without whose contribution this study would have been more limited in information and less substantial in terms of impact.

I also want to acknowledge the representatives of the National Human Rights Institutions (NHRI) for their support and kind contribution to the study and for allowing me to benefit from their valuable and insightful expertise in the field of 
promoting and protecting human rights. Although, for objective reasons, it turned out to be a collateral preoccupation of my research, the feedback on the potential negative impact of gamification on violation of human rights showed me that the ethical approach of gamified education is, indeed, a subject that cannot be ignored.

This article was elaborated within the Human Capital Operational Program 2014-2020, co-financed by the European Social Fund, under the project POCU/380/6/13/124708 no. 37141/23.05.2019, with the title "ResearcherEntrepreneur on Labor Market in the Fields of Intelligent Specialization (CERTANTREP)", coordinated by the National University of Political Studies and Public Administration.

\section{REFERENCES}

- Alomari, Islam, Hosam Al-Samarraie, and Reem Yousef. 2019. "The role of gamification techniques in promoting student learning: A review and synthesis". Journal of Information Technology Education: Research. Vol. 18 (August 2019): 395-417. https:// doi.org/10.28945/4417.

- Bénabou, Roland, and Jean Tirole. 2003. "Intrinsic and Extrinsic Motivation". The Review of Economic Studies. Vol. 70. No. 3 (July 2003): 489520.

https://www.researchgate.net/publication/4918104_Intrinsic_and_Extrins ic_Motivation/link/5ed04e1e92851c9c5e65e1e5/download.

- Boulet, Guy. 2016. "Gamification Is Simply Bells and Whistles". eLearn. No. 11 (November 2016). https:// doi.org/10.1145/3017608.3013524.

- Buck, Mark Fabian. 2017. "Gamification of Learning and Teaching in Schools - A Critical Stance". Seminar.net - International journal of media, technology and lifelong learning. Vol. 13. No. 1 (January 2017). https://doi.org/10.7577/seminar.2325 .

- Cheng, Yuh Ming, Shi-Jer Lou, Shen-Huang Kuo, and Ru-Chu Shih. 2013. "Investigating elementary school students' technology acceptance by applying digital game-based learning to environmental education". 
Australasian Journal of Educational Technology. Vol. 29. No. 1 (March, 2013). https://doi.org/10.14742/ajet.65

- Clark, Douglas B., Emily E. Tanner-Smith, and Stephen S. Killingsworth. 2016. "Digital games, design, and learning: A systematic review and metaanalysis". Review of Educational Research. Vol. 86. No.1 (March 2016): 79-122. https://doi.org/10.3102/0034654315582065

- Detering, Sebastian, Rilla Khaled, Lennart E. Nacke, and Dan Dixon. 2011. "Gamification: Toward a definition". CHI 2011 Gamification Workshop Proceedings. Vancouver, BC, Canada. http://gamification-research.org/wpcontent/uploads/2011/04/02-Deterding-Khaled-Nacke-Dixon.pdf

- Dichev, Christo, and Darina Dicheva. 2017. "Gamifying education: what is known, what is believed and what remains uncertain: a critical review". International Journal of Education Technology Higher Education. No. 14. 9 (February 2017). https://doi.org/10.1186/s41239-017-0042-5

- Hyrynsalmi, Sami, Jouni Smed, and Kai K. Kimppa. 2017. “The Dark Side of Gamification: How We Should Stop Worrying and Study also the Negative Impacts of Bringing Game Design Elements to Everywhere", GamiFIN Conference 2017. Pori, Finland, May 9-10, 2017. http://ceurws.org/Vol-1857/gamifin17_p13.pdf

- Jones, Sherry. 2015. "The Ethics of Gamification and Gamified Learning". Presentation on issues and research regarding gamification in higher education for the e-Learning Consortium of Colorado (eLCC) conference. April 16, 2015. http://bit.ly/gameethics

- Kim, Tae W., and Kevin Werbach. 2016. "More than Just a Game: Ethical Issues in Gamification". Ethics and Information Technology. Vol. 18. No. 2 (June 2016): 157-173. http:/ / dx.doi.org/10.1007/s10676-016-9401-5

- Majuri, Jenni, Jonna Koivisto, and Juho Hamari. 2018. "Gamification of education and learning: A review of empirical literature". GamiFIN Conference 2018. Pori, Finland, May 21-23, 2018. https://www.researchgate.net/publication/327438074_Gamification_of_E ducation_and_Learning_A_Review_of_Empirical_Literature

- Marczewski, Andrzej. 2013. "Gamification: a simple introduction: Tips, advice and thoughts of gamification". Self-published E-Book. 2 edition.

- Navarro, Jose I., Esperanza Marchena, Conception Alcalde, Gonzalo Ruiz, Iker Llorens, and Manuel Aguilar. 2003. “Improving attention behaviour in primary and secondary school children with a computer assisted 
instruction procedure". International Journal of Psychology. Vol 38. No. 6 (December 2003): 359-365. https://doi.org/10.1080/00207590244000042 .

- Ofosu-Ampong, Kingsley. 2020. "The Shift to Gamification in Education: A Review on Dominant Issues". Journal of Educational Technology Systems. Vol. 49. No. 1 (April 2020): 113-137. https://journals.sagepub.com/doi/pdf/10.1177/0047239520917629.

- Prensky, Marc. 2001. “Digital Game-Based Learning”. Chapter II: The Games Generations: How Learners Have Changed. McGraw-Hill. https:/ / marcprensky.com/writing/Prensky\%20-\%20Ch2Digital\%20Game-Based\%20Learning.pdf.

- Rootman-le Grange, Ilse, Magda Barnard, and Samantha P. Adams. 2016. "The Ethics of Gamification: Playing Games with Students". Conference: International Consortium for Educational Development ICED 2016. Cape Town, November 2016. https://www.researchgate.net/publication/313420032_The_Ethics_of_Ga mification_Playing_Games_with_Students.

- Tang, Stephen, Martin Hanneghan, and Abdennour El Rhalibi. 2009. "Introduction to Games-Based Learning". Games-Based Learning Advancements for Multi-Sensory Human Computer Interfaces: Techniques and Effective Practices. 1st ed., K. Klinger, Ed. IGI Global

https://www.academia.edu/2222412/Introduction_to_games_based_learn ing.

- Toda, Armando M., Petro H. D. Valle, and Seiji Isotani. 2018. "The Dark Side of Gamification: An Overview of Negative Effects of Gamification". Cristea A., Bittencourt I., Lima F. (eds) Higher Education for All. From Challenges to Novel Technology-Enhanced Solutions. HEFA 2017. Communications in Computer and Information Science. vol 832. Springer. August 208: 143-156. https://doi.org/10.1007/978-3-319-97934-2_9 .

- Versteeg, Chiel. 2013. Ethics \& Gamification design: a moral framework for taking responsibility. Masterthesis: New Media \& Digital Culture. http://dspace.library.uu.nl:8080/handle/1874/281831

- Woo, Jeng-Chung. 2014. "Digital Game-Based Learning Supports Student Motivation, Cognitive Success, and Performance Outcomes". Educational Technology \& Society. Vol. 17. No.3 (July 2013): 291-307. http:// citeseerx.ist.psu.edu/viewdoc/download?doi=10.1.1.566.12\&rep=re p1\&type=pdf. 
- Zhonggen, Yu. 2019. "A Meta-Analysis of Use of Serious Games in Education over a Decade". International Journal of Computer Games Technology. Volume 2019. No. 1 (February 2019): 1-8. https://doi.org/10.1155/2019/4797032. 